\title{
Fatigue in children and adolescents perinatally infected with human immunodeficiency virus: an observational study
}

\section{Anne Marleen ter Haar ( $\square$ a.m.terhaar@amsterdamumc.nl )}

Emma Kinderziekenhuis AMC Locatie AMC: Emma Kinderziekenhuis Amsterdam UMC https://orcid.org/0000-0002-9165-9454

\section{Merel M. Nap-van der Vlist}

Wilhelmina Children's Hospital University Medical Centre: Universitair Medisch Centrum Utrecht - Locatie Wilhelmina Kinderziekenhuis

\section{Malon Van den Hof}

Emma Childrens Hospital AMC: Emma Kinderziekenhuis Amsterdam UMC

\section{Sanne L. Nijhof}

Wilhelmina Children's Hospital University Medical Centre: Universitair Medisch Centrum Utrecht - Locatie Wilhelmina Kinderziekenhuis

\section{Raphaële R. L. van Litsenburg}

Princess Maxima Center for Pediatric Oncology: Prinses Maxima Centrum voor Kinderoncologie

\section{Kim J. Oostrom}

Emma Childrens Hospital AMC: Emma Kinderziekenhuis Amsterdam UMC

\section{Dasja Pajkrt}

Emma Childrens Hospital AMC: Emma Kinderziekenhuis Amsterdam UMC

\section{Research article}

Keywords: Perinatal HIV, Vertical HIV, HIV-infection, Pediatric, Child, Adolescent, Fatigue, Quality of Life, Health-related Quality of Life

Posted Date: May 26th, 2021

DOI: https://doi.org/10.21203/rs.3.rs-551260/v1

License: (c) (1) This work is licensed under a Creative Commons Attribution 4.0 International License. Read Full License 


\section{Abstract \\ Background}

Fatigue is common among adults living with human immunodeficiency virus (HIV) as well as children with a chronic disease (CCD). Fatigue can have disastrous effects on health status, including health related quality of life (HRQOL). Even so, fatigue is underexplored in children and adolescents perinatally infected with HIV (PHIV+) in the Netherlands. This study aims to explore fatigue in PHIV + and its association with their HRQOL.

\section{Methods}

We measured HRQOL and fatigue using the Pediatric Quality of Life Inventory ${ }^{\text {TM }}$ (PedsQL 4.0) and the PedsQL Multidimensional Fatigue Scale (MFS). The PedsQL MFS encompasses three subscales: general fatigue, sleep/rest fatigue and cognitive fatigue, and a total fatigue score. We compared outcomes of PHIV + with three groups: 1) HIV-uninfected controls (HIV-) matched for age, sex, socioeconomic status and adoption status, 2) CCD, and 3) the general Dutch population. Within the PHIV + group we explored associations between fatigue and HRQOL.

\section{Results}

We enrolled 14 PHIV+ (median age 10.2 years [IQR 9.2-11.4]) and 14 HIV-. Compared to CCD, PHIV + significantly reported less general fatigue (mean difference $13.0,95 \% \mathrm{Cl} 1.3$ to 24.8 ). PHIV + did not score significantly different on any of the other PedsQL MFS scales compared to HIV-, CCD or the general Dutch population. PHIV children scored relatively low on the cognitive fatigue scale in comparison to HIVuninfected matched controls, CCD and the general population, although these differences did not reach significance. Among PHIV+, a lower score on total fatigue, sleep/rest fatigue and cognitive fatigue was associated with a lower HRQOL score.

\section{Conclusions}

The results of this study suggest that PHIV children and adolescents do not experience more symptoms of fatigue than their healthy peers. However, PHIV children and adolescents may be more likely to experience cognitive fatigue. Fatigue in PHIV also appears to be associated with children's HRQOL. Further research should confirm these exploratory findings.

\section{Introduction}

Children and adolescents perinatally infected with HIV (PHIV+) are provided with advanced supportive healthcare in the Netherlands. This results in generally favorable outcomes, with a low mortality rate and 
good long-term virological and immunological responses to treatment (1). Still, undesirable outcomes remain even in optimally treated and clinically stable PHIV+, including cognitive problems, lower IQ, and lower health related quality of life (HRQOL) (2-4). Since PHIV + can now be considered a chronic condition, there is a need to carefully monitor symptoms that are common amongst children living with a chronic disease (CCD) (5-8). Fatigue is one of these commonly reported symptoms in CCD (9). Likewise, fatigue is a common and disabling symptom among adult people living with HIV (PLWH) $(10,11)$. However, we know little about symptoms of fatigue in children and adolescents with PHIV+.

Fatigue is a multidimensional construct, encompassing cognitive, behavioral, emotional and physiological aspects (12). In children and adolescents with chronic disease, fatigue does not appear to be a disease-specific process (9) and can persist despite low disease activity (13). Similarly, in PLWH, disease and treatment related factors (such as duration of HIV infection, use of antiretroviral therapy (ART), or laboratory parameters) form only a part of the etiology of fatigue (11). Fatigue in PLWH appears more clearly linked to psychosocial factors including cognition (14), which is found to be poorer in PHIV+ $(3,4)$.

Experiencing fatigue on a daily basis can have a detrimental effect on concentration, focus and emotional well-being $(15,16)$. Subsequently, this can lead to school absence, poor academic achievement and restrictions in social interactions with peers $(17,18)$. Among adult PLWH, fatigue has been found to affect adherence to ART, possibly due to its disruptive impact on daily routines and on concentration and memory (19-21). Fatigue can lead to adverse health outcomes and a lower health-related quality of life (HRQOL), and is thus an important and disabling symptom (22).

Studies have shown a high prevalence of fatigue in children with chronic disease as well as adult PLWH $(9,10)$, yet it has only been systematically studied in one adolescent group of PLWH in South Africa (15, $23,24)$. Within this group, about a quarter to half of the adolescents living with HIV demonstrated problematic levels of fatigue (23). Since children or adolescents who acquired HIV perinatally have been living with the disease and using cART from an early age, they are likely to face different challenges and have different health needs compared with young adults with behaviorally acquired HIV (25).

Furthermore, substantial cultural differences regarding fatigue in children have been reported, precluding generalization of previous study results to PHIV + living in the western world $(26,27)$. No evidence is out there reporting on fatigue in children or adolescents who acquired HIV perinatally and are living in the western world.

Considering the high prevalence of fatigue in CCD and PLWH and the existing risk factors for developing fatigue in PHIV+, it is likely that fatigue is a prevalent symptom in PHIV+. This is important to know, as timely recognition and treatment of fatigue can decrease its burden and could prevent fatigue from continuing into adulthood $(11,28-30)$.

Therefore, the primary aim of this study is to investigate the extent of fatigue among PHIV + children and adolescents. To reach this aim, we compared the symptoms of fatigue in PHIV + to a control group matched for age, gender, SES and adoption status. To understand whether the extent and nature of 
fatigue symptoms in PHIV + are similar to those of the general Dutch population or children with chronic disease, we used these two groups as a reference. In addition, we investigated the association between fatigue and HRQOL.

\section{Materials And Methods}

\section{Participants and procedure}

This cross-sectional study was part of the observational NOVICE cohort study investigating the effect of perinatal HIV infection and the exposure of combination antiretroviral therapy (CART) on neurological, cognitive and visual performances conducted at the Amsterdam University Medical Centers (AUMC), University of Amsterdam, the Netherlands (2-4,31-35). Among all PHIV + children in the outpatient department of our hospital we newly recruited those who were 12 years or older between February 2017 and July 2018 (34). Inclusion and exclusion criteria for the NOVICE-cohort are described in more detail elsewhere (36). HIV-uninfected controls were recruited from the same communities and frequency matched to PHIV + regarding age, sex, ethnicity and socioeconomic status (SES) and region of birth (2, 34). To match groups for adoption status and region of adoption, we newly recruited HIV-uninfected controls through two government-licensed adoption organizations (3). We obtained written informed consent from participants 12 years and older and from all parents or legal guardians of participants younger than 18 years old. The ethics committee of the Amsterdam University Medical Center approved the study protocol.

\section{Questionnaires}

We measured fatigue using the Dutch self-report version of the Pediatric Quality of Life Inventory ${ }^{\mathrm{TM}}$ (PedsQL) Multidimensional Fatigue Scale (PedsQL MFS) for children aged 8-12 years and 13-18 years (37-40). The PedsQL MFS was designed to measure fatigue in patients with acute and chronic health conditions as well as healthy populations. It includes 18 items, divided over three subscales: General Fatigue (six items, e.g., 'I feel tired'; 'I feel too tired to do things that I like to do'); Sleep/Rest Fatigue (six items, e.g., 'I feel tired when I wake up in the morning'; 'I rest a lot'); and Cognitive Fatigue (six items, e.g., 'It is hard for me to keep my attention on things'; 'It is hard for me to remember what people tell me'). The subscales are summarized into a Total Fatigue score. Items are rated on a 5-point Likert scale $(0=$ "never a problem", $1=$ "almost never a problem", 2 = "sometimes a problem", 3 = "often a problem", and 4 = "nearly always a problem") based on the preceding week. Items are reverse scored and linearly transformed to a 0-100 scale so that higher scale scores indicate fewer symptoms of fatigue. In this study, internal consistency reliability was $\alpha>0.80$ for Total Fatigue and the Sleep/Rest Fatigue and Cognitive Fatigue subscales, and $a=0.52$ for the General Fatigue subscale (41).

We compared fatigue outcomes of PHIV + with three groups: (1) a matched group of HIV-uninfected controls included in this study (as described above), (2) a reference group of children and adolescents from the general Dutch population and (3) a reference group of children and adolescents with chronic disease (CCD). Data of the reference group of the general population were previously collected at day 
care facilities and schools in the Netherlands (40). This group consisted of 502 children, with a median age of $10.0(5-13)$ years and $239(47.6 \%)$ were male.

Data of CCD were previously collected as part of the PROactive study (9) and included children with cystic fibrosis, autoimmune diseases, and children who completed treatment for cancer. CCD were 481 children with a median age of 11.0 (IQR 6-15) years, 202 (42\%) were male.

We measured Health-Related Quality of Life (HRQOL) in PHIV + and HIV-uninfected controls using the Dutch child self-report version of the generic Pediatric Quality of Life Inventory ${ }^{\mathrm{TM}} 4.0$ (PedsQL ${ }^{\mathrm{TM}},(42)$ ). The PedsQL includes 23 items, rated on a similar Likert scale as the PedsQL MFS. The items are divided over four subscales: physical functioning (eight items), emotional functioning (five items), social functioning (five items), and school functioning (five items). The subscales are summarized into the psychosocial health summary score (including the emotional, social, and school functioning subscales) and a total score (including all subscales). Higher scores indicate higher HRQOL and better functioning. In this study, internal consistency reliability was $a>0.80$ for the total score (41).

Sociodemographic, adoption and HIV- and cART-related characteristics

For PHIV + and matched HIV-uninfected controls, we collected data on age, sex, ethnicity, region of birth, education level of (adoptive) parents (scored according to the International Standard Classification of Education [ISCED (43) and number of parents with a job. ISCED is scored from 0 to 9 , ranging from less than primary education to doctoral or equivalent level. SES was defined as level of parental education and parental occupational status. Parental education was scored according to the International Standard Classification of Education Occupational status was defined as 0,1 , or 2 caregivers with a paid job (2).

For PHIV + children, we performed laboratory testing of HIV-1 viral load (VL) and CD4 + T-cell count. The Dutch HIV Monitoring Foundation provided historical data (age at HIV diagnosis, route of HIV transmission, age at CART initiation duration of CART, time between HIV diagnosis and CART initiation) and data since registration in the Netherlands (AIDS-defining clinical events, Centers for Disease Control and Prevention [CDC] clinical staging, nadir CD4 + T-cell z-score, zenith VL). We defined CART as use of at least three antiretroviral drugs from two or more classes. In the HIV-uninfected control group HIV-testing was performed to confirm their HIV- uninfected status.

\section{Data analysis}

We compared sociodemographic characteristics (as reported in Table 1) between PHIV+-participants and HIV-uninfected matched controls by using the unpaired t-test or Mann-Whitney $U$ test, and Fischer's exact test for categorical data. We presented normally distributed data as mean \pm standard deviation (SD); otherwise, we provided median and interquartile range (IQR). We used regression analysis to explore differences in fatigue scores between PHIV + and the three other groups. We used Shapiro-Wilk and Q-Q plots to check the assumption of normality. Since age and sex are associated with fatigue $(24,40)$, we adjusted the regression model for these variables. We present adjusted and unadjusted mean differences 
(see Additional file 1, Table 1) using the mean difference, represented by unstandardized beta, and 95\% confidence interval $(\mathrm{Cl})$. Within the PHIV + group, we used linear regression to investigate the association between fatigue and HRQOL. We performed all statistical analyses in IBM SPSS Statistics (version 25). We did not adjust for multiple comparisons, since we considered these analyses to be exploratory.

\section{Results}

\section{Participants}

We identified nineteen PHIV + children from the outpatient department of our hospital, of whom five (28\%) declined consent and one (5\%) did not meet the inclusion criteria. Thirteen (68\%) provided consent to participate. We additionally included one PHIV + child, receiving care in another treatment centre, whose adoptive parents approached us in response to the advertisements for healthy adopted controls. We present relevant sociodemographic characteristics of PHIV + children and matched HIV- uninfected controls in Table 1. PHIV + and HIV-uninfected matched controls did not significantly differ in age, sex, ethnicity, SES or adoption status. All participants completed the questionnaires entirely. 
Table 1

Demographics of Perinatally Human Immunodeficiency Virus infected (PHIV+) children and HIV uninfected (HIV-) matched controls

\begin{tabular}{|c|c|c|c|c|c|}
\hline Characteristics & $\mathrm{n}$ & PHIV+ & $\mathbf{n}$ & HIV- & $P^{a}$ \\
\hline Number of participants & & 14 & & 14 & \\
\hline Male sex & 14 & $5(35.7 \%)$ & 14 & $7(50.0 \%)$ & 0.710 \\
\hline Age, y, median (IQR) & 14 & $10.2(9.2-11.4)$ & 14 & $\begin{array}{l}10.0(8.1- \\
11.5)\end{array}$ & 0.571 \\
\hline Region of birth & 14 & 1 & 14 & 0 & 0.174 \\
\hline Asia & & 13 & & 10 & \\
\hline Sub-Sahara Africa & & 0 & & 2 & \\
\hline Eastern Europe & & 0 & & 2 & \\
\hline \multicolumn{6}{|l|}{ Central America } \\
\hline Adopted & 14 & $13(93 \%)$ & 14 & $12(86 \%)$ & 0.541 \\
\hline ISCED highest, median (IQR) & 13 & 2 & 14 & 0 & 0.248 \\
\hline $0-2$ & & 7 & & 7 & \\
\hline $3-5$ & & 4 & & 7 & \\
\hline \multicolumn{6}{|l|}{$6-8$} \\
\hline Number of parents with a job & 13 & 6 & 13 & 2 & 0.202 \\
\hline 1 & & 7 & & 10 & \\
\hline \multicolumn{6}{|c|}{2} \\
\hline Age at HIV diagnosis (y), median (IQR) & 14 & $2.10(0.33-3.45)$ & & & \\
\hline Perinatal transmission, $\mathrm{n}(\%)$ & 14 & $14(100 \%)$ & & & \\
\hline CDC category $\mathbb{\|}, n(\%)$ N/A & 14 & $12(86 \%)$ & & & \\
\hline N/A & & $1(7 \%)$ & & & \\
\hline B & & $1(7 \%)$ & & & \\
\hline C & & & & & \\
\hline
\end{tabular}

Values are reported as $n(\%)$, unless otherwise stated. Undetectable is defined as HIV RNA $<40 \mathrm{c} / \mathrm{mL}$, and allowing viral blips. Values are reported as mean (SD), median (IQR) or $n(\%)$. Abbreviations: $n$, number; PHIV+, perinatally human immunodeficiency virus infected; HIV-, HIV-uninfected controls; $y$, year; IQR, interquartile range; ISCED, International Standard Classification of Education; Centers for Disease Control and Prevention; N, not symptomatic; A, mildly symptomatic; B, moderately symptomatic; $\mathrm{C}$, severely symptomatic; $\mathrm{VL}$, viral load; $\mathrm{mL}$, milliliter; $\mathrm{cART}$, combination antiretroviral therapy; SD, standard deviation; mo, month. 


\begin{tabular}{|c|c|c|c|c|}
\hline Characteristics & $\mathbf{n}$ & PHIV+ & HIV- & $P^{a}$ \\
\hline 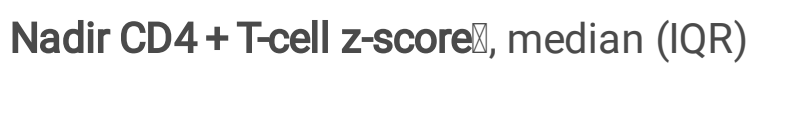 & 14 & $\begin{array}{l}-0.76(-1.35 \text { to } \\
-0.13)\end{array}$ & & \\
\hline Zenith HIV VL (copies/mL) $ه$, median (IQR) & 14 & $\begin{array}{l}107492(265- \\
296408)\end{array}$ & & \\
\hline cART, n (\%) & 14 & $14(100 \%)$ & & \\
\hline Age at cART initiation (y), median (IQR) & 14 & $3.07(1.06-5.41)$ & & \\
\hline Duration of cART use (y), mean (SD) & 14 & $6.79(2.56)$ & & \\
\hline $\begin{array}{l}\text { HIV diagnosis to cART initiation (mo), } \\
\text { median (IQR) }\end{array}$ & 14 & $\begin{array}{l}22.92(4.00- \\
59.38)\end{array}$ & & \\
\hline Undetectable HIV VL at assessment, $\mathrm{n}(\%)$ & 14 & $14(100 \%)$ & & \\
\hline \multicolumn{5}{|c|}{$\begin{array}{l}\text { Values are reported as } n(\%) \text {, unless otherwise stated. Undetectable is defined as HIV RNA }<40 \mathrm{c} / \mathrm{mL} \text {, } \\
\text { and allowing viral blips. Values are reported as mean (SD), median (IQR) or } \mathrm{n}(\%) \text {. Abbreviations: } \mathrm{n} \text {, } \\
\text { number; PHIV+, perinatally human immunodeficiency virus infected; HIV-, HIV-uninfected controls; } y \text {, } \\
\text { year; IQR, interquartile range; ISCED, International Standard Classification of Education; Centers for } \\
\text { Disease Control and Prevention; N, not symptomatic; } A \text {, mildly symptomatic; B, moderately } \\
\text { symptomatic; C, severely symptomatic; VL, viral load; mL, milliliter; cART, combination antiretroviral } \\
\text { therapy; SD, standard deviation; mo, month. }\end{array}$} \\
\hline
\end{tabular}

QSince registration in the Netherlands.

Fatigue

Table 2 and Fig. 1 present the PedsQL MFS scores of PHIV + and HIV-uninfected matched controls for each separate scale. PHIV + and HIV-uninfected matched controls did not significantly differ on any of the PedsQL MFS scores. Mean differences (adjusted for age and gender) and $95 \% \mathrm{Cl}$ are presented in Table 2. 
Table 2

PedsQL MFS Scores in PHIV + and HIV-

\begin{tabular}{|c|c|c|c|c|}
\hline & PHIV+ $(n=14)$ & HIV- $(n=14)$ & $\mathrm{BD}$ & $95 \% \mathrm{Cl}$ \\
\hline Fatigue total & $78.57 \pm 11.23$ & $82.54 \pm 12.93$ & -4.520 & -14.1 to 5.1 \\
\hline General fatigue & $85.71 \pm 8.91$ & $86.00 \pm 12.30$ & -0.870 & -9.5 to 7.7 \\
\hline Sleep/rest fatigue & $79.17 \pm 16.59$ & $81.85 \pm 19.31$ & -4.502 & -15.4 to 6.4 \\
\hline Cognitive fatigue & $70.83 \pm 20.15$ & $79.76 \pm 16.57$ & -8.187 & -22.9 to 6.5 \\
\hline \multicolumn{5}{|c|}{$\begin{array}{l}\text { Fatigue scores are reported as mean } \pm \text { SD. B represents mean difference between PHIV }+ \text { and the } \\
\text { comparison group, adjusted for age and sex. Lower scores indicate more fatigue; a negative } B \\
\text { therefore means more fatigue in PHIV + compared to HIV-. Abbreviations: } n \text {, number; PedsQL MFS, } \\
\text { PedsQL multidimensional fatigue scale; PHIV+, perinatally human immunodeficiency virus infected; } \\
\text { HIV-, HIV-uninfected matched controls }\end{array}$} \\
\hline
\end{tabular}

Figure 1. Mean Scale scores on PEDSQL MFS of PHIV+, HIV-, CCD and Dutch GP

Lower scores indicate more severely fatigued. Error bars represent $95 \%$ confidence intervals. Abbreviations: n, number; CCD, Children with chronic Disease; GP, General Population; PedsQL MFS; PedsQL multidimensional fatigue scale; PHIV+, perinatally human immunodeficiency virus infected; HIV-, HIV-uninfected matched controls

Table 3 presents mean differences (adjusted for age and gender) and 95\% $\mathrm{Cl}$ between PHIV+, CCD and the general Dutch population.

Compared to CCD, PHIV + children and adolescents scored less fatigued with respect to general fatigue (mean difference: 13.0 points; $95 \% \mathrm{Cl} 1.3$ to 24.8 ). PHIV + and CCD did not significantly differ on any of the other PedsQL MFS scores.

In comparison to the general Dutch population, PHIV + children and adolescents did not score significantly different on any of the PedsQL MFS scales.

PHIV + children scored relatively low on the cognitive fatigue scale in comparison to HIV-uninfected matched controls, CCD and the general Dutch population, although these differences did not reach significance. 
Table 3

Mean differences in PedsQL MFS Scores between PHIV + and HIV-, CCD and Dutch GP

\begin{tabular}{|c|c|c|c|c|}
\hline & \multicolumn{2}{|c|}{$\operatorname{CCD}(n=481)$} & \multicolumn{2}{|c|}{ Dutch GP $(n=502)$} \\
\hline & $\mathrm{B} \bigotimes$ & $95 \% \mathrm{Cl}$ & $\mathrm{B} \triangle$ & $95 \% \mathrm{Cl}$ \\
\hline Fatigue total & 4.613 & -4.8 to 14.0 & 0.837 & -5.8 to 7.5 \\
\hline General fatigue & 13.029 & 1.3 to 24.8 & 5.333 & -1.9 to 12.6 \\
\hline Sleep/rest fatigue & 7.906 & -2.6 to 18.4 & 3.091 & -4.9 to 11.0 \\
\hline Cognitive fatigue & -7.109 & -18.1 to 3.9 & -5.948 & -15.6 to 3.7 \\
\hline \multicolumn{5}{|c|}{$\begin{array}{l}\text { *B represents mean difference between PHIV + and the comparison group, adjusted for age and sex. } \\
\text { Lower scores indicate more severely fatigued; a negative score therefore means more fatigue in } \\
\text { PHIV+. Significant differences in bold. Abbreviations: n, number; CCD, Children with chronic Disease; } \\
\text { GP, General Population; PedsQL MFS, PedsQL multidimensional fatigue scale; PHIV+, perinatally } \\
\text { human immunodeficiency virus infected; HIV-, HIV-uninfected matched controls. }\end{array}$} \\
\hline
\end{tabular}

Health-related Quality of Life

PHIV + and HIV-uninfected matched controls did not significantly differ on any of the HRQOL scores (see Additional file 1, Table 2). Within the PHIV + group, having a lower score on the total fatigue scale was significantly associated with a lower total HRQOL score (see Table 4). For each 1-point reduction in the PedsQL MFS score, the HRQOL was on average 0.73 points lower ( $95 \% \mathrm{Cl} 0.37$ to 1.10$)$. A lower score on total HRQOL was also associated with general fatigue (B 1.03; $95 \% \mathrm{Cl} 0.7$ to 1.4$)$ and cognitive fatigue (B $0.33 ; 95 \% \mathrm{Cl} 0.1$ to 0.6$)$, but not with sleep/rest fatigue.

Table 4

Association between PedsQL MFS and HRQOL in PHIV+.

\begin{tabular}{|c|c|c|}
\hline & \multicolumn{2}{|c|}{ HRQOL Total } \\
\hline & $\mathrm{B} \otimes$ & $95 \% \mathrm{Cl}$ \\
\hline Fatigue total & 0.733 & 0.4 to 1.1 \\
\hline General fatigue & 1.028 & 0.7 to 1.4 \\
\hline Sleep/rest fatigue & 0.227 & -0.1 to 0.6 \\
\hline Cognitive fatigue & 0.328 & 0.1 to 0.6 \\
\hline \multicolumn{3}{|c|}{$\begin{array}{l}\varangle \mathrm{B} \text { represents the decrease in HRQOL score for each 1-point reduction in the PedsQL MFS score } \\
\text { (indicating more fatigue). Significant differences in bold. PedsQL MFS; PedsQL multidimensional } \\
\text { fatigue scale, HRQOL; Health-related quality of life. }\end{array}$} \\
\hline
\end{tabular}

\section{Discussion}


The results of this study suggest that PHIV + children and adolescents do not experience more fatigue than healthy peers. In PHIV + children, symptoms of fatigue are associated with HRQOL.

These results are not in line with earlier studies reporting a high prevalence of fatigue symptoms in children and adolescents living with HIV in South-Africa as well as in adults living with HIV in the Western world $(10,11,15,23,24)$. Neither do the symptoms of fatigue in PHIV + look like those of another pediatric population with chronic disease, who generally experience more fatigue than the general population in all domains, except for cognitive fatigue (9). On the contrary, in our study cognitive fatigue appeared to be the only domain that might be most affected in PHIV + children and adolescents.

These findings of low levels of fatigue in PHIV + might be because the majority of PHIV + children and adolescents in the Netherlands are treated optimally from an early age (44). Consequently, most PHIV + children have never (consciously) suffered from any HIV symptoms, in contrast to children with other chronic disease. Furthermore, the mean age of the population in this study is relatively low. While fatigue in PLWH is linked to psychosocial variables such as a depressed mood and cognitive functioning and the burden of these psychosocial variables increase as they grow up into adolescence and young adulthood, their experience of fatigue might increase too $(11,14,36,45-47)$. In the healthy population, fatigue fluctuates naturally over the course of development and is more common in late adolescence $(40,48)$. The same fluctuation of fatigue with age is found in adolescent PLWH (24). We therefore suggest future studies should include older adolescents and young adults perinatally infected with HIV.

PHIV + children and adolescents tended to report relatively more cognitive fatigue compared to all three reference groups. We previously reported a lower IQ and poorer cognitive profiles in this group, which might influence the reported cognitive fatigue $(3,4)$. We therefore explored associations of cognitive fatigue with neuropsychological outcomes (IQ and Hotelling's T). Indeed, these analysis showed a positive association between cognitive measures and cognitive fatigue (see Additional file 1, Table 3 ). Cognitive fatigue might arise as a result of increased cognitive demands, or the cognitive fatigue scale might be a proxy of perceived cognitive impairment more than fatigue specifically (12). The association between fatigue and cognition is likely to be reciprocal, while it has been shown that experiencing cognitive fatigue can lead to a decrease in cognitive functioning, such as mental flexibility and planning (49-51). This reciprocal relationship exposes the potential that treating fatigue could also have a positive effect on cognitive functioning. Treatment options such as cognitive behavioral therapy, exercise interventions and multifaceted treatment have shown promising results in other pediatric populations experiencing fatigue (52-54).

It is important to note that the small sample size of this study prohibits us from drawing firm conclusions about the occurrence of fatigue in PHIV+. Firstly, the small sample leads to a reduced change of detecting a significant difference between PHIV + and other groups when the true effect is small and variance is large (55). The possibility of an existing effect can therefore not be dismissed. Simultaneously, it reduces the likelihood that a statistically significant result reflects a true effect. Therefore, we emphasize the importance of the suggestion of more cognitive fatigue in PHIV + compared to all three groups, over any 
individually occurring significant outcomes. In small samples outliers can severely skew outcomes and might have to be eliminated from analyses. In our sample we found no outliers and therefore we included all data.

The age and sex distribution in the reference groups were not exactly the same as in the PHIV + group ( 9 , 40). We attempted to compensate for this difference by adjusting our analyses for sex and age. We did not find any evidence that either influenced the results.

\section{Conclusions}

In conclusion, the results of this study suggest that optimally treated PHIV + children and adolescents do not experience more symptoms of fatigue then their healthy peers, although they do seem more likely to experience cognitive fatigue. These results need to be confirmed in studies with larger samples and in older populations of PHIV + adolescents and young adults. Still, since fatigue is associated with healthrelated quality of life, we encourage health care practitioners to be attentive to symptoms of (cognitive) fatigue in PHIV + children and adolescents.

\section{Abbreviations}

ART Antiretroviral therapy

cART Combination antiretroviral therapy

CCD Children with Chronic Disease

CDC Centers for Disease Control and Prevention

Cl Confidence interval

HIV Human immunodeficiency virus

HIV- HIV-uninfected matched controls

HRQOL Health related quality of life

IQR Interquartile Range

ISCED International Standard Classification of Education

PedsQL Pediatric Quality of Life Inventory

PedsQL MFS PedsQL Inventory Multidimensional Fatigue Scale

PHIV + Perinatally HIV infected

Page $12 / 18$ 
PLWH People living with HIV

SES Socioeconomic status

SD Standard deviation

VL Viral Load

\section{Declarations}

\section{Ethics Approvaland consent to participate}

This study was performed in line with the principles of the Declaration of Helsinki. The ethics committee of the Amsterdam University Medical Center has provided a written approval for the study protocol. Approval number: NL58216.018.16. Informed consent was obtained from participants 12 years and older and from all parents or legal guardians of participants younger than 18 years old.

\section{Consent for publication}

Not applicable.

\section{Availability of data and materials}

All data generated during this study are included in additional file 2 of this article. Previously collected data on reference groups study are available from $M N, S N$ and $R L$, but restrictions apply to the availability of these data and are not publicly available.

\section{Competing interests}

The authors declare that they have no competing interest.

\section{Funding}

This study was funded by the Dutch Aidsfonds (Grant number 2015009, made available to the last author). The funder had no role in the design of the study and collection, analysis, interpretation of data or in writing the manuscript.

\section{Authors' contributions}

$\mathrm{AH}, \mathrm{MH}$ and DP contributed to the study conception and design. Data collection was performed by $\mathrm{AH}$ and $\mathrm{MH}$ and analysis were performed by $\mathrm{AH}$. Data on norm populations was provided by MN, SN and RL. The first draft of the manuscript was written by A.H. and all authors commented on previous versions of the manuscript. All authors read and approved the final manuscript.

\section{Acknowledgements}


The authors thank all study participants and their parents; and HIV pediatric nurses at the outpatient department.

\section{References}

1. van Sighem AIW, F.W.N.M.; Boyd, A.; Smit, C., Matser, A.; Reiss P. Monitoring Report 2019. Human Immunodeficiency Virus (HIV) Infection in the Netherlands. Amsterdam: Stichting HIV Monitoring; 2019.

2. Cohen S, ter Stege JA, Weijsenfeld AM, van der Plas A, Kuijpers TW, Reiss P, et al. Health-related quality of life in perinatally HIV-infected children in the Netherlands. AIDS Care. 2015;27(10):1279-88.

3. Van den Hof M, Ter Haar AM, Scherpbier HJ, Reiss P, Wit F, Oostrom KJ, et al. Lower IQ and poorer cognitive profiles in treated perinatally HIV-infected children is irrespective of having a background of international adoption. PLoS One. 2019;14(12):e0224930.

4. Van den Hof M, Ter Haar AM, Scherpbier HJ, van der Lee JH, Reiss P, Wit F, et al. Neurocognitive development in perinatally HIV-infected adolescents on long-term treatment compared to healthy matched controls: a longitudinal study. Clin Infect Dis. 2019.

5. Lowenthal ED, Bakeera-Kitaka S, Marukutira T, Chapman J, Goldrath K, Ferrand RA. Perinatally acquired HIV infection in adolescents from sub-Saharan Africa: a review of emerging challenges. The Lancet Infectious diseases. 2014;14(7):627-39.

6. Mellins $\mathrm{CA}$, Malee KM. Understanding the mental health of youth living with perinatal HIV infection: lessons learned and current challenges. J Int AIDS Soc. 2013;16:18593.

7. Mofenson LM, Cotton MF. The challenges of success: adolescents with perinatal HIV infection. J Int AIDS Soc. 2013;16:18650.

8. Vreeman RC, Scanlon ML, McHenry MS, Nyandiko WM. The physical and psychological effects of HIV infection and its treatment on perinatally HIV-infected children. J Int AIDS Soc. 2015;18(Suppl 6):20258.

9. Nap-van der Vlist MM, Dalmeijer GW, Grootenhuis MA, van der Ent CK, van den Heuvel-Eibrink MM, Wulffraat NM, et al. Fatigue in childhood chronic disease. Arch Dis Child. 2019;104(11):1090-5.

10. Hughes AM, Campbell L, Graham H, Post F, Chalder T. A Biopsychosocial Approach to HIV Fatigue: A Cross-Sectional and Prospective Analysis to Identify Key Modifiable Factors. Behav Med. 2020:1-9.

11. Cook PF, Hartson KR, Schmiege SJ, Jankowski C, Starr W, Meek P. Bidirectional Relationships Between Fatigue and Everyday Experiences in Persons Living With HIV. Res Nurs Health. 2016;39(3):154-63.

12. Fatigue as a Window to the Brain. Cambridge, Massachusetts: MIT Press; 2005.

13. Nijhof LN, van de Putte EM, Wulffraat NM, Nijhof SL. Prevalence of Severe Fatigue Among Adolescents With Pediatric Rheumatic Diseases. Arthrit Care Res. 2016;68(1):108-14.

14. Barroso J, Voss JG. Fatigue in HIV and AIDS: an analysis of evidence. J Assoc Nurses AIDS Care. 2013;24(1 Suppl):S5-14. 
15. Loades ME, Coetzee B, Du Toit S, Kagee A. ' ... But I'm still tired': The experience of fatigue among South African adolescents receiving antiretroviral therapy. AIDS Care. 2018;30(6):746-50.

16. Bileviciute-Ljungar I, Schult ML, Borg K, Ekholm J. Preliminary ICF core set for patients with myalgic encephalomyelitis/chronic fatigue syndrome in rehabilitation medicine. J Rehabil Med. 2020;52(6):jrm00074.

17. Fowler T, Duthie P, Thapar A, Farmer A. The definition of disabling fatigue in children and adolescents. BMC Fam Pract. 2005;6:33.

18. Sankey A, Hill CM, Brown J, Quinn L, Fletcher A. A follow-up study of chronic fatigue syndrome in children and adolescents: symptom persistence and school absenteeism. Clin Child Psychol Psychiatry. 2006;11(1):126-38.

19. Gay C, Portillo CJ, Kelly R, Coggins T, Davis H, Aouizerat BE, et al. Self-reported medication adherence and symptom experience in adults with HIV. J Assoc Nurses AIDS Care. 2011;22(4):257-68.

20. Wagner GJ, Goggin K, Remien RH, Rosen MI, Simoni J, Bangsberg DR, et al. A closer look at depression and its relationship to HIV antiretroviral adherence. Ann Behav Med. 2011;42(3):352-60.

21. Molassiotis A, Nahas-Lopez V, Chung WY, Lam SW, Li CK, Lau TF. Factors associated with adherence to antiretroviral medication in HIV-infected patients. Int J STD AIDS. 2002;13(5):301-10.

22. Haverman L, Limperg PF, van Oers HA, van Rossum MA, Maurice-Stam H, Grootenhuis MA. Psychometric properties and Dutch norm data of the PedsQL Multidimensional Fatigue Scale for Young Adults. Qual Life Res. 2014;23(10):2841-7.

23. Coetzee B, Loades ME, Du Toit S, Read R, Kagee A. Fatigue among South African adolescents living with HIV: Is the Chalder Fatigue Questionnaire a suitable measure and how common is fatigue? Vulnerable children and youth studies. 2018;13(4):305-16.

24. Coetzee BJ, Loades ME, Du Toit S, Kagee A. Correlates of Fatigue Among South African Adolescents Living with HIV and Receiving Antiretroviral Therapy. AIDS and behavior. 2019;23(3):602-8.

25. Writing group for the Kids to Adults Working Group and Data Management and Harmonisation Group in EuroCoord. Children and young people with perinatal HIV in Europe: epidemiological situation in 2014 and implications for the future. Euro Surveill. 2016;21(10):pii=30162.

26. Roberts RE, Roberts CR, Chen IG. Ethnocultural differences in sleep complaints among adolescents. J Nerv Ment Dis. 2000;188(4):222-9.

27. LeBourgeois MK, Giannotti F, Cortesi F, Wolfson AR, Harsh J. The relationship between reported sleep quality and sleep hygiene in Italian and American adolescents. Pediatrics. 2005;115(1 Suppl):257-65.

28. Loades ME, Kagee A. Exploring our understanding of fatigue among adolescents living with HIV: Highlighting the unknown. Journal of health psychology. 2019;24(1):125-36.

29. Lamers F, Hickie I, Merikangas KR. Prevalence and correlates of prolonged fatigue in a U.S. sample of adolescents. Am J Psychiatry. 2013;170(5):502-10.

30. Nijhof SL, Priesterbach LP, Uiterwaal CS, Bleijenberg G, Kimpen JL, van de Putte EM. Internet-based therapy for adolescents with chronic fatigue syndrome: long-term follow-up. Pediatrics. 
2013;131(6):e1788-95.

31. Blokhuis C, Demirkaya N, Cohen S, Wit FW, Scherpbier HJ, Reiss P, et al. The Eye as a Window to the Brain: Neuroretinal Thickness Is Associated With Microstructural White Matter Injury in HIV-Infected Children. Investigative Ophthalmology \& Visual Science. 2016;57(8):3864-71.

32. Blokhuis C, Mutsaerts HJ, Cohen S, Scherpbier HJ, Caan MW, Majoie CB, et al. Higher subcortical and white matter cerebral blood flow in perinatally HIV-infected children. Medicine (Baltimore). 2017;96(7):e5891.

33. Cohen S, Caan MW, Mutsaerts HJ, Scherpbier HJ, Kuijpers TW, Reiss P, et al. Cerebral injury in perinatally HIV-infected children compared to matched healthy controls. Neurology. 2016;86(1):1927.

34. Cohen S, Ter Stege JA, Geurtsen GJ, Scherpbier HJ, Kuijpers TW, Reiss P, et al. Poorer cognitive performance in perinatally HIV-infected children versus healthy socioeconomically matched controls. Clin Infect Dis. 2015;60(7):1111-9.

35. Van den Hof M, Blokhuis C, Cohen S, Scherpbier HJ, Wit F, Pistorius MCM, et al. CNS penetration of ART in HIV-infected children. J Antimicrob Chemother. 2018;73(2):484-9.

36. ter Haar AM, Van den Hof M, Scherpbier HJ, van der Lee JH, Reiss P, Wit FWNM, et al. Neurocognitive Development in Perinatally Human Immunodeficiency Virus-infected Adolescents on Long-term Treatment, Compared to Healthy Matched Controls: A Longitudinal Study. Clinical Infectious Diseases. 2019.

37. Varni JW, Burwinkle TM, Szer IS. The PedsQL Multidimensional Fatigue Scale in pediatric rheumatology: reliability and validity. J Rheumatol. 2004;31(12):2494-500.

38. Varni JW, Limbers CA, Bryant WP, Wilson DP. The PedsQL multidimensional fatigue scale in pediatric obesity: feasibility, reliability and validity. Int J Pediatr Obes. 2010;5(1):34-42.

39. Varni JW, Limbers CA, Bryant WP, Wilson DP. The PedsQL Multidimensional Fatigue Scale in type 1 diabetes: feasibility, reliability, and validity. Pediatr Diabetes. 2009;10(5):321-8.

40. Gordijn MS, Cremers, E. M. P., Kaspers, G. J. L. and Gemke, R. J. B. J. Fatigue in children: reliability and validity of the Dutch PedsQL ${ }^{\mathrm{TM}}$ Multidimensional Fatigue Scale. Quality of Life Research. 2011;20(7):1103-9.

41. Cronbach LJ. Test reliability; its meaning and determination. Psychometrika. 1947;12(1):1-16.

42. Varni JW BT, Seid M, Skarr D. The PedsQL 4.0 as a pediatric population health measure: feasibility, reliability, and validity. Ambul Pediatr. 2003;3:329-41.

43. UNESCO. International standard classification of education ISCED 2011. Montreal, Canada: United Nations Educational, Scientific and Cultural Organization Institute for Statistics; 2012.

44. Monitoring SH. Annual Report 2018. 2019.

45. Rydström L-L, Wiklander M, Navér L, Ygge B-M, Eriksson LE. HIV-related stigma and health-related quality of life among children living with HIV in Sweden. AIDS Care. 2016;28(5):665-71. 
46. Gadow. Longitudinal Study of Emerging Mental Health Concerns in Youth Perinatally Infected With HIV and Peer Comparisons.pdf>. 2012.

47. Weijsenfeld AM, Smit C, Cohen S, Wit FWNM, Mutschelknauss M, van der Knaap LC, et al. Virological and Social Outcomes of HIV-Infected Adolescents and Young Adults in The Netherlands Before and After Transition to Adult Care. Clin Infect Dis. 2016;63(8):1105-12.

48. ter Wolbeek M, van Doornen LJ, Kavelaars A, Heijnen CJ. Severe fatigue in adolescents: a common phenomenon? Pediatrics. 2006;117(6):e1078-86.

49. van der Linden D, Frese, M., Meijman, Theo F. Mental Fatigue and the Control of Cognitive processes: Effects on Perseveration and Task Engagement. Acta Psychologica. 2003;113(1):45 - 65.

50. Nijhof LN, Nijhof SL, Bleijenberg G, Stellato RK, Kimpen JL, Hulshoff Pol HE, et al. The impact of chronic fatigue syndrome on cognitive functioning in adolescents. Eur J Pediatr. 2016;175(2):245-52.

51. Gullett JM, Cohen RA, Yang GS, Menzies VS, Fieo RA, Kelly DL, et al. Relationship of fatigue with cognitive performance in women with early-stage breast cancer over 2 years. Psychooncology. 2019;28(5):997-1003.

52. Robinson PD, Oberoi S, Tomlinson D, Duong N, Davis H, Cataudella D, et al. Management of fatigue in children and adolescents with cancer and in paediatric recipients of haemopoietic stem-cell transplants: a clinical practice guideline. Lancet Child Adolesc Health. 2018;2(5):371-8.

53. Chang CW, Mu PF, Jou ST, Wong TT, Chen YC. Systematic review and meta-analysis of nonpharmacological interventions for fatigue in children and adolescents with cancer. Worldviews Evid Based Nurs. 2013;10(4):208-17.

54. Collard SS, Murphy J. Management of chronic fatigue syndrome/myalgic encephalomyelitis in a pediatric population: A scoping review. J Child Health Care. 2020;24(3):411-31.

55. Button KS, loannidis JP, Mokrysz C, Nosek BA, Flint J, Robinson ES, et al. Power failure: why small sample size undermines the reliability of neuroscience. Nat Rev Neurosci. 2013;14(5):365-76.

\section{Figures}




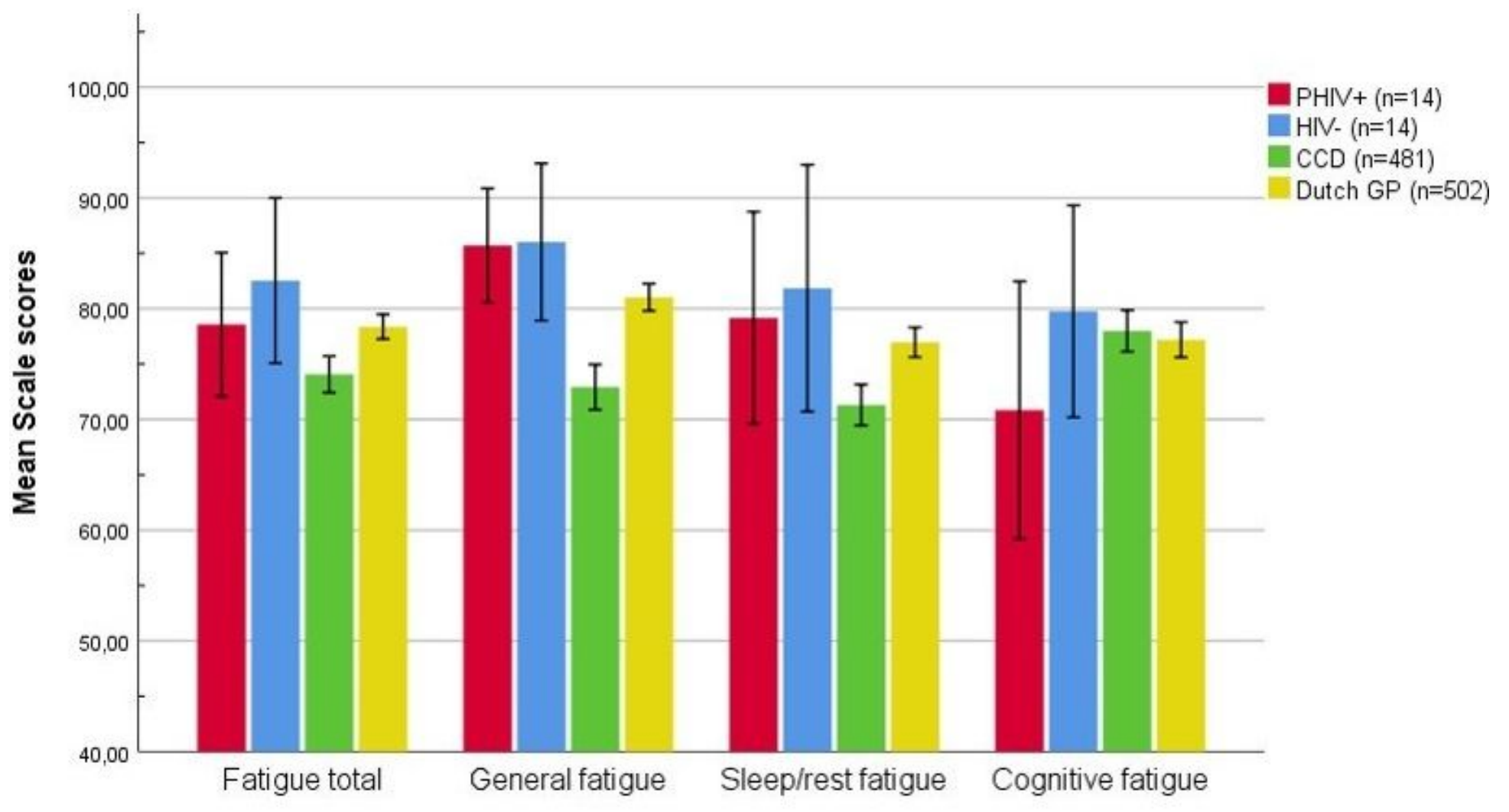

Figure 1

\section{Supplementary Files}

This is a list of supplementary files associated with this preprint. Click to download.

- Additionalfile1.docx

- Additionalfile2.xlsx 